\title{
BORDERLINE OF VIABILITY:
}

\section{WHERE ARE WE?}

Fateh Singh ${ }^{2}$, Shree Vishna Rasiah ${ }^{1}$, Anju Singh ${ }^{1}$

1 Birmingham Women's and Children's NHS Foundation Trust, United Kingdom

2 Medical School, Newcastle University, United Kingdom

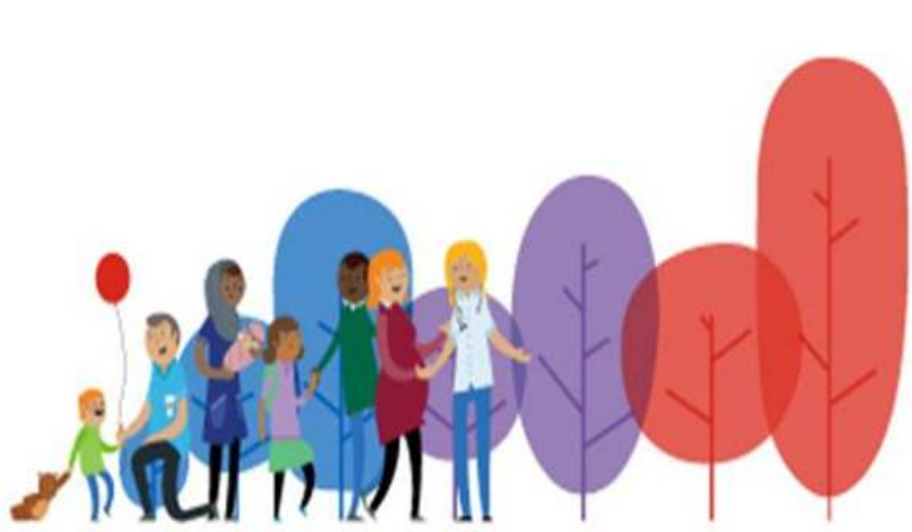

\section{BACKGROUND}

- Advances in the Neonatal Intensive Care Unit (NICU) have improved neonatal survival rates and lowered limits of viability.

- Survival outcomes at the borderline of viability (22-23 weeks) are still poor, with variation between units.

- Nuffield council ${ }^{1}$ and British Association of Perinatal Medicine $^{2}$ have provided national guidance on management of these babies.

- EPICure $2^{3}$ survival figures help in the antenatal counselling of families.

\section{AIMS}

The aim of this study was to review local morbidity and mortality figures at Birmingham Women's Hospital NICU to aid clinicians and families with decision-making.

\section{MethODS}

Retrospective data was collected using BadgerNet database. The outcomes of 22-23 week gestation babies born between 1st April 2009 and 31st March 2018 were reviewed.

\section{2-WEEKERS}

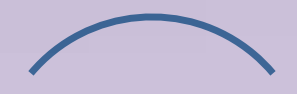

5 babies

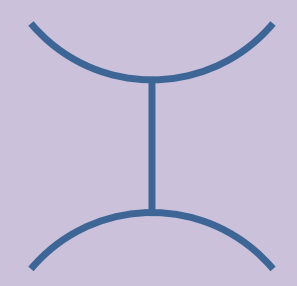

5 died

(0\% survival)

\section{Comorbidities in surviving babies}

\begin{tabular}{|c|c|c|}
\hline & Total & Percentage \\
\hline $\begin{array}{l}\text { IVH Grade } 3 \text { or } \\
\text { more/ PVL }\end{array}$ & 8 & $28 \%$ \\
\hline $\begin{array}{l}\text { NEC/Perforation } \\
\text { (requiring Surgery) }\end{array}$ & 6 & $21 \%$ \\
\hline ROP (requiring laser) & 11 & $38 \%$ \\
\hline Home Oxygen & 10 & $35 \%$ \\
\hline
\end{tabular}

\section{RESULTS}

- There were 82 babies born at 23 weeks gestation in the study period.

- All 5 babies born at 22 weeks gestation did not survive beyond 3 weeks.

- 29 babies were discharged home.

- The comorbidities noted in surviving babies: Necrotising Enterocolitis (NEC) or intestinal perforation requiring surgery; Intraventricular Haemorrhage (IVH) Grade 3 or more/ Periventricular Leukomalacia (PVL); Retinopathy of Prematurity (ROP) which required laser treatment; and chronic lung disease needing home oxygen on discharge. These are outlined in the table.

\section{3-WEEKERS}

82 Babies

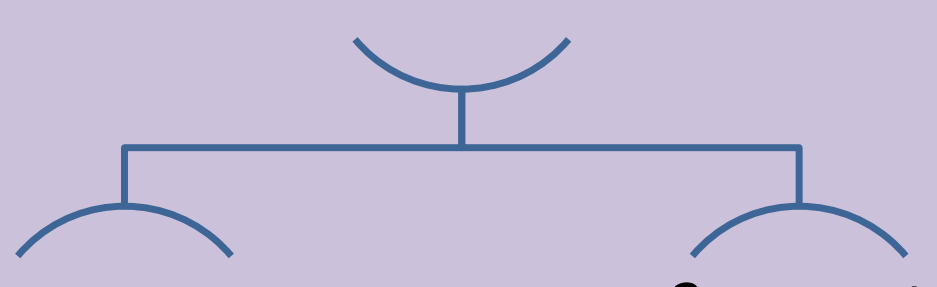

3 current

79 babies included

inpatients excluded

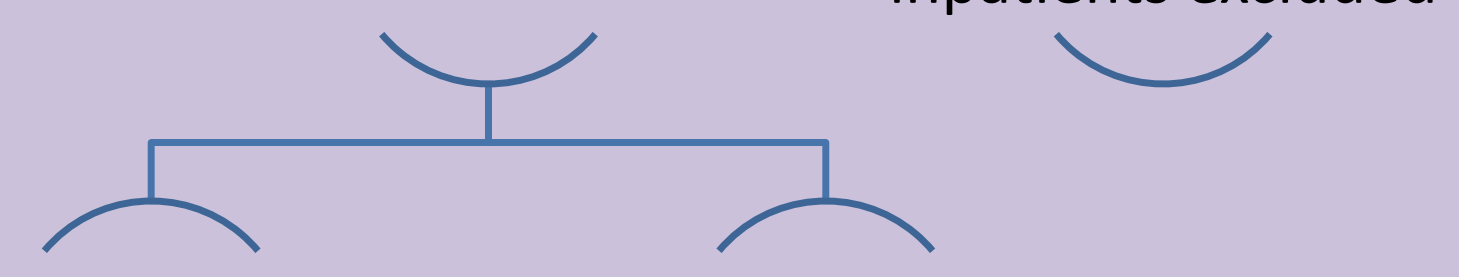

22 Out-born

57 Inborn

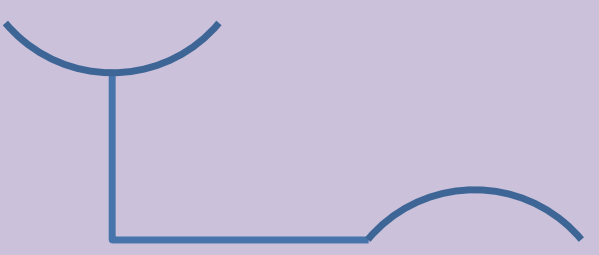

13 survived (59\%)

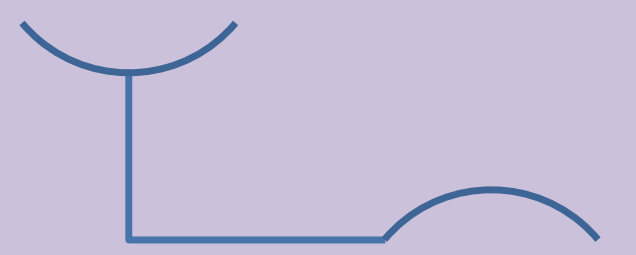

16 Survived (28\%)
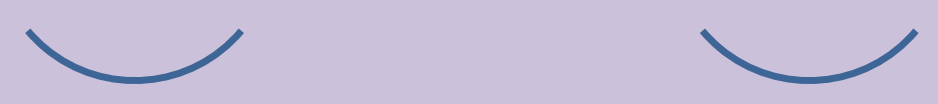

\section{CONCLUSIONS}

- Our findings suggest that intensive care is unlikely to benefit babies born at 22 weeks gestation given their poor prognosis.

- In 23-weekers, our in-born survival is slightly higher than the EPICure $2^{3}(20 \%)$. The higher survival in the out-born babies is likely to be a reflection of the unit being a surgical and medical referral centre for the surviving 23-weekers .

- Survivors had a high incidence of significant co-morbidities.

- The local data will be useful for antenatal counselling.

\section{REFERENCES}

1. Nuffield Council on Bioethics. Critical care decision in fetal and neonatal medicine: ethical issues. 2006 [cited 2012 August 27]. Available from: http://www.nuffieldbioethics.org

2. Wilkinson AR, Ahluwalia J, Cole A, Crawford D, Fyle J, Gordon A, et al. Management of babies born extremely preterm at less than 26 weeks of gestation: a framework for clinical practice at the time of birth. Arch Dis Child Fetal Neonatal Ed. 2009; 94(1):F2-5.

3. EPICure 2 Perinatal Group. Survival and early morbidity of extremely preterm babies in England: changes since1995. Arch Dis Child 2008; 93:(Supp 1):A33-34 